\author{
A CALCULATION OF THE $\mathrm{Na}^{22}$ PRODUCED IN THE \\ SOIL AND IN GROUND WATER IN THE VICINITY OF THE \\ NEUTRINO LABORATORY AT NAL \\ T. E. Toohig \\ March 1971
}

\begin{abstract}
A calculation based on experimental data is made of $\mathrm{Na}^{22}$ activity produced in the vicinity of the Neutrino Laboratory Target Tube and Meson Decay Pipe. Using conservative assumptions it is found that the annual production of leachable $\mathrm{Na}^{22}$ is of the order of $5.7 \mathrm{~m} \mathrm{Ci} /$ linear foot of the facility or a total of $7.5 \mathrm{Ci}$ over the entire 1300 feet. With the ground water control system designed for the facility, the total $\mathrm{Na}^{2} 2$ activity reaching the aquifer per year is the order of $\leq 70 \mu \mathrm{Ci}$, or $1 \mathrm{MPC}$ if dissolved in about $\leq 4500$ liters of water as compared with the $2 \times 10^{10}$ liters/yr. of rainfall on the site. No measurable activity above the naturally occurring levels should be found at the site boundary, even under extreme operating conditions of the accelerator.
\end{abstract}


The reliance on earth shielding for target areas at NAL gives rise to a question of possible radioactive contamination of ground water moving through the shields and entering underground water supply systems. This problem has been studied at the existing $25-30 \mathrm{GeV}$ accelerators at BNL and CERN ${ }^{1}$ and at lower energy installations, and no evidence of such contamination has been found in the ten years of their operation. This non-observation gives a scale for the magnitude of the potential problem at NAI. Scaling intensity and energy, the potential problem at NAL is of the order of 100 times worse than at the lower energy machines. Since the effect is below threshold at the lower energies, we know that the problem even at its worst still lies within manageable bounds at NAL. We do not enter some totally mysterious region. We are also far below the levels encountered in problems of radioactive waste disposal and successfully handled for some twenty years at various installations. ${ }^{2}$ The problem has also been studied in connection with studies for the $300-\mathrm{GeV}$ project in Europe ${ }^{3}$ and a calculation based on this has been done for the accelerator proper at NAI. ${ }^{4}$

The factors that enter into the evaluation of the extent of the ground water activation problem are:

1) the beam intensity and energy deposited in the area

2) particle production dynamics and nuclear cascade development at these energies.

3) the chemical composition and disposition of the material being irradiated. 
4) the local flow of ground water past the radiation zone

5) the flow of ground water from the vicinity of the radiation zone to the edges of the site. To some extent all of these factors except for 2) and 5) are under our control either in the construction phase 3) and 4) or in the operational phase 1). Some control of 5) can be achieved subsequent to construction by appropriate drilling and pumping.

To the extent that 2), above, can be understood, factors 3) and 4) will be used through appropriate construction techniques and materials to control any potential local ground water problems in the immediate vicinity of the beam dumps. An over-all analysis of the details of the ground water irradiation problem, then, follows.

To avoid possible groundwater contamination due to operation of the Neutrino Laboratory facility at NAI, a conservative system for controlling the groundwater flow in the vicinity of the Target Tube and Meson Decay Pipe has been designed, and modified by the addition of deep underdrains in line with suggestions of the Illinois Water Survey. ${ }^{5}$ This system for the Decay Pipe is illustrated in cross-section in Fig. 1. Figure 2, on a different scale, indicates how the decay region is situated relative to the shielding berm and the surrounding ground level. A similar arrangement with a larger cross-section is used to control the flow of groundwater in the vicinity of the Target Tube upstream of the Decay 
Pipe. The entire radiation region - Target Tube plus Decay Pipe is $400 \mathrm{~m}(\sim 1300$ feet) in length.

The material within the impermeable membrane indicated in Fig. 1 is bank run sand and gravel fill. The membrane rests, as indicated, on glacial till, and the whole is covered with a shielding berm consisting of soil from the NAL site. The $\Delta r=4$ feet dashed circles in Fig. 1 indicate the accepted shielding increment for a reduction of 1 decade in hadron flux, $\lambda_{t} \lesssim 100 \mathrm{gm} / \mathrm{cm}^{2} \cdot{ }^{6,7}, 8$ Since activation is linear with flux, the percentages shown on the circles in Fig. 1 are the percentages of total activation within the circles on the assumption of homogeneous shielding material. The 5:1 sloping dashed lines from the underdrains in Fig. 1 indicate the approximate draw-down regions for these underdrains. Essentially all ground water above these slopes is collected by the drains. Under the same assumption of homogeneous shielding material, only $0.03 \%$ of the total activity is produced outside the control region for the underdrain system shown. To convert the percentages of Fig. 1 to absolute numbers, we make use of the data from the side shield experiment in the $30 \mathrm{GeV}$ extracted proton beam at BNL as given in Fig. 3. It is possible to make a first-order approximation by looking at the estimates of production of protons and neutrons into the solid angle subtended by various segments of the decay pipe. The relevant number, though, is the propagation of the transverse component of this flux, which is extremely difficult to extract by calculations of interactions. 
By using the measured side shield data we obviate this difficulty. The conditions for the BNL experiment were similar to those that will obtain in the Neutrino Laboratory, i.e. a thick target $(0.4 \lambda)$ in an extracted beam with the residual beam continuing far downstream. The isoflux contours of Fig. 3 are given in terms of strongly interacting particles per incident proton. The data were obtained by $\mathrm{C}^{11}$ activation techniques with an activation threshold of $20 \mathrm{MeV} . \mathrm{Na}^{22}$ has a threshold of $30 \mathrm{MeV}$, so the BNL contours must be corrected to account for the difference in thresholds. Because the mean transverse momentum in high energy collisions is approximately constant with energy, we will assume that the same isoflux contours will hold at higher energies if one makes a correction for the dependence of particle multiplicity on energy, $E^{\frac{1}{2}}$. (Cosmic ray data give $E^{\frac{1}{4}}$. Ranft calculates $E$ 0.7 $)^{10}$. $E^{\frac{1}{2}}$ gives a factor of 4 at $400 \mathrm{GeV}$ relative to $30 \mathrm{GeV}$. We will assume further that the isoflux contours do not converge downstream, but are parallel to the Decay Pipe along its entire length. The radii of contours are assumed to be those at the shoulder of the $30 \mathrm{GeV}$ contours, scaled as indicated. These are conservative assumptions. Finally, the assumed operating conditions for the machine are $10^{13} \mathrm{p} / \mathrm{sec}$, at $400 \mathrm{GeV}$, with a $100 \%$ duty factor.

\section{Particle Fluxes}

We will use five feet of soil, the nearest point of the impermeable membrane to the decay pipe, as our reference point for the calculations. 


$$
\begin{aligned}
& t\left(5^{\prime} \text { of soil }\right)=305 \mathrm{gm} / \mathrm{cm}^{2} \\
& 305 \mathrm{gm} / \mathrm{cm}^{2} \approx 15 \text { inches of } \mathrm{Fe} \\
& \left(15^{\prime} \text { of } \mathrm{Fe}\right) \approx 6 \times 10^{-6} \text { particles } / \mathrm{cm}^{2} / \mathrm{sec} / \mathrm{p} \\
& \text { at the maximum of the shoulder in } \mathrm{Fig} .3 .
\end{aligned}
$$

The slope of the neutron spectrum in soil is ${ }^{8}$

$$
\mathrm{E}^{-1.8} \text {, so }
$$

$\phi_{15^{\prime \prime}}(\mathrm{E}>30 \mathrm{MeV})=\phi_{15 "}(\mathrm{E}>\mathrm{MeV})\left[1-\left(\int_{20}^{30} \frac{\mathrm{dE}}{\mathrm{E}^{1.8}} / \int_{2}^{\infty} \frac{\mathrm{dE}}{\mathrm{E}^{1.8}}\right)\right]$

Uncorrected for geometry

$\phi_{15^{\prime \prime}}(\mathrm{E}>30 \mathrm{MeV}) \approx 4.3 \times 10^{-6}$ particles $/ \mathrm{cm}^{2} / \mathrm{sec} /$ incident

proton

Assuming a geometric fall off of $\frac{1}{r}$

$\phi_{5 ' \text { soil }}(E>30 \mathrm{MeV}) \approx_{10^{-6}}$ part $/ \mathrm{cm}^{2} / \mathrm{sec} / \mathrm{in} . \mathrm{p}$.

We can correct this back to $r=18^{\prime \prime}$ to obtain an apparent

source term at the pipe, assuming a uniform medium.

Let $r_{0}=18^{\prime \prime}, \lambda=50 \mathrm{~cm}$

$r_{5}, \phi_{5},=r_{0} \phi_{0} e^{-\left(r_{5}-r_{0}\right) / \lambda}$

$\phi_{0}=\frac{r_{5}, \phi_{5}, e^{+\left(r_{5}-r_{0}\right) \lambda}}{r_{0}}$

$\phi_{0}=3.06 \times 10^{-6}$ part $/ \mathrm{cm}^{2} / \mathrm{sec} /$ incident $\mathrm{p}$

$\phi_{0}=3.06 \times 10^{8} \mathrm{part} / \mathrm{cm}^{2} / \mathrm{sec} / 10^{13}$ protons 
2. $\mathrm{Na}^{22}$ Activity

$$
\begin{aligned}
& A(t)=\int_{0}^{400 m} d l \int_{r_{0}}^{\infty} 2 \pi r d r \frac{r_{0} \phi_{0}}{r} e^{-\left(r-r_{0}\right) / \lambda} \sigma N\left(1-e^{-0.693 t / \tau}\right) \\
& =2 \pi r_{0} \phi_{0} l \sigma N\left(1-e^{-0.693 t / \tau}\right) e^{r_{0} / \lambda} \int_{r_{0}^{\infty}}^{\infty} e^{-r / \lambda} \mathrm{dr} / 3.7 \times 10^{10} \\
& r_{0}=18 " \text {, the radius of the decay pipe } \\
& \ell=400 \mathrm{~m} \text {, the length of the decay pipe } \\
& \sigma=10 \text { mbarns, the spallation cross-section for } \mathrm{Al}^{27} \rightarrow \mathrm{Na}^{22}(11,12) \\
& \mathrm{N}=\mathrm{A} I^{27} \text { atoms } / \mathrm{cm}^{3} \text { of } \mathrm{NAL} \text { soil (6\% } \mathrm{Al} \text { by wgt.) } \\
& =1.8 \times 10^{21} \text { atoms } / \mathrm{cm}^{3}
\end{aligned}
$$

$1 \mathrm{Ci}=3.7 \times 10^{10} \mathrm{dis} / \mathrm{sec}$

$\mathrm{A}(1 \mathrm{yr})=.29.2 \mathrm{Ci} / \mathrm{Yr}$. from $\mathrm{Al}^{27}$ assuming homogeneous soil fill. $\mathrm{A}(1 \mathrm{yr}.) \approx 150 \mathrm{Ci} / \mathrm{yr}$ from all $\mathrm{Na}^{22}$ sources allowing for the difference in threshold between $\mathrm{Al}$ and $\mathrm{Si}$.

From Fig. 1, $0.03 \%$ of the activity is outside the

water control system and, from Awschalom's data, $\lesssim 10 \%$ of $\mathrm{Na}^{22}$

in the till is leachable. The activity in the uncollected groundwater is then:

$$
\begin{aligned}
& A_{g \cdot w}=150 \times 3 \times 10^{-4} \times 0.10 \\
& A_{g \cdot w .} \approx 4.5 \mathrm{mCi} \text { in situ per year. }
\end{aligned}
$$

Also from Fig. 1, <5\% of the activity is in the soil outside the sand and gravel fill, so the actual total leachable activity is $A_{\text {total }} \lesssim 7.5 \mathrm{Ci}$ assuming no leachable $\mathrm{Na}^{22}$ in the sand and gravel.

According to the Illinois Water Survey the upper range of the rate of flow of water in the till is 
$.01-.02 \mathrm{ft} . /$ day $=3.65-7.3 \mathrm{ft} . / \mathrm{yr}$. Ions travel at something less than one-half the rate of the water $\lesssim 1.8-3.6 \mathrm{ft} . / \mathrm{yr}$.

$$
\begin{aligned}
t_{\text {travel }} & \gtrsim \frac{56 \mathrm{ft} .}{2.5 \mathrm{ft} \cdot / \mathrm{yr} \cdot \frac{1}{2.6 \mathrm{yr} .}} \\
& \gtrsim 12.0-6.0 \text { half-lives }
\end{aligned}
$$

or a reduction of $2.4 \times 10^{-2}-1.6 \times 10^{-2}$. Therefore the activity/yr. reaching the aquifer from the whole target and decay region is

$$
A_{\text {aquifer }} \approx 1.0 \mu \mathrm{Ci} / \mathrm{yr} .-70 \mu \mathrm{Ci} / \mathrm{yr}
$$

This compares with the concentration of $13 \mathrm{nCi} / \mathrm{l}$ for $1 \mathrm{MPC}$ of $\mathrm{Na}^{22}$. The entire year's production reaching the aquifer could, then, be diluted in 60-4500 liters of water.

Put in another way, when we consider that the average use of water is $100 \mathrm{gal} /$ day per person, if all of the activity reaching the aquifer were to find its way in some unlikely way into a single well serving one person that water would still be somewhere between 20 to 1500 times below the Maximum Permissible Concentration for $\mathrm{Na}^{22}$. 


$$
\begin{array}{ll}
-8- & T M-284-A \\
& 1101.300 \\
& 1101200
\end{array}
$$

References

1

Mawson, C. A., "Consequences of Radioactive Disposals into the Ground", in Health Physics, Vol. 2, part 1, A.M.F. Duhamel, ed. , 1969.

2

Hoyer, F. E., "Induced Radioactivity in the Earth Shielding on Top of High-Energy Particle Accelerators", CERN Report 68-42, 1968 .

3

Stapleton, G. H., and Thomas, R. H., "Estimation of the Inducea Radioactivity of the Ground Water system in the Neighborhood of a Proposed $300 \mathrm{GeV}$ High Energy Accelerator Situated on a Chalk Site." RHEL/R Report (to be published).

Thomas, R. H., "Possible Contamination of Ground Water System by High Energy Proton Accelerators", Proceedings of the Topical Symposium on the Health Physics Aspects of Nuclear Facility Siting, December 3-6, 1970 (also UCRI-20131).

Schicht, R. J., "Report on Vertical Movement of Water in Glacial Drift in the Vicinity of Target Area at the National Accelerator Laboratory near Batavia, Illinois", Illinois state Water survey Report, January 7, 1971 transmittal from H. F. Smith, Head of the Hydrology Section.

6

Bennett, G. W., et.al., "Flux Attenuation in a steel side Shield at the AGS", Proceedings of the 1971 Particle Accelerator Conference, March 1-3, 1971.

7

Goebel, K., and Ranft, J., "Radiation Measurements around a Beam Stopper Irradiated by $19.2 \mathrm{GeV} / \mathrm{C}$ Protons, and Neutron Energy Spectra from Monte Carlo Nucleon-Meson Cascade Calculations", CERN Report 70-16.

8

Gilbert, W. S., et.al., "1966 CERN-LRL-RHEL Shielding Experiment at the CERN Proton Synchrotron", UCRL-17971.

Smith, H. F., private communication January 17, 1971. 10

Jones. L. W., et.al., "Charged-Particle Multiplicities of ProtonProton Interactions Between 90 and $800 \mathrm{GeV}$." Phys. Rev. Letters, 29, (1970), p. 1679 . 
11

Charalambus, S., et.al., "Particle Flux Measurements with Activation Detectors", CERN/DI/HP90, 1966.

12 van Ginneken, A., " $\mathrm{Na}^{2} 2$ production Cross Section in Soil" NAI TM-283-1971.

13 Awschalom, M. et.al., "The Underground Water Leaching of Radionuclides Produced in Soil by Hadrons Created in High Energy Proton Interactions", Proceedings of the 1971 Particle Accelerator Conference, March 1-3, 1971. 


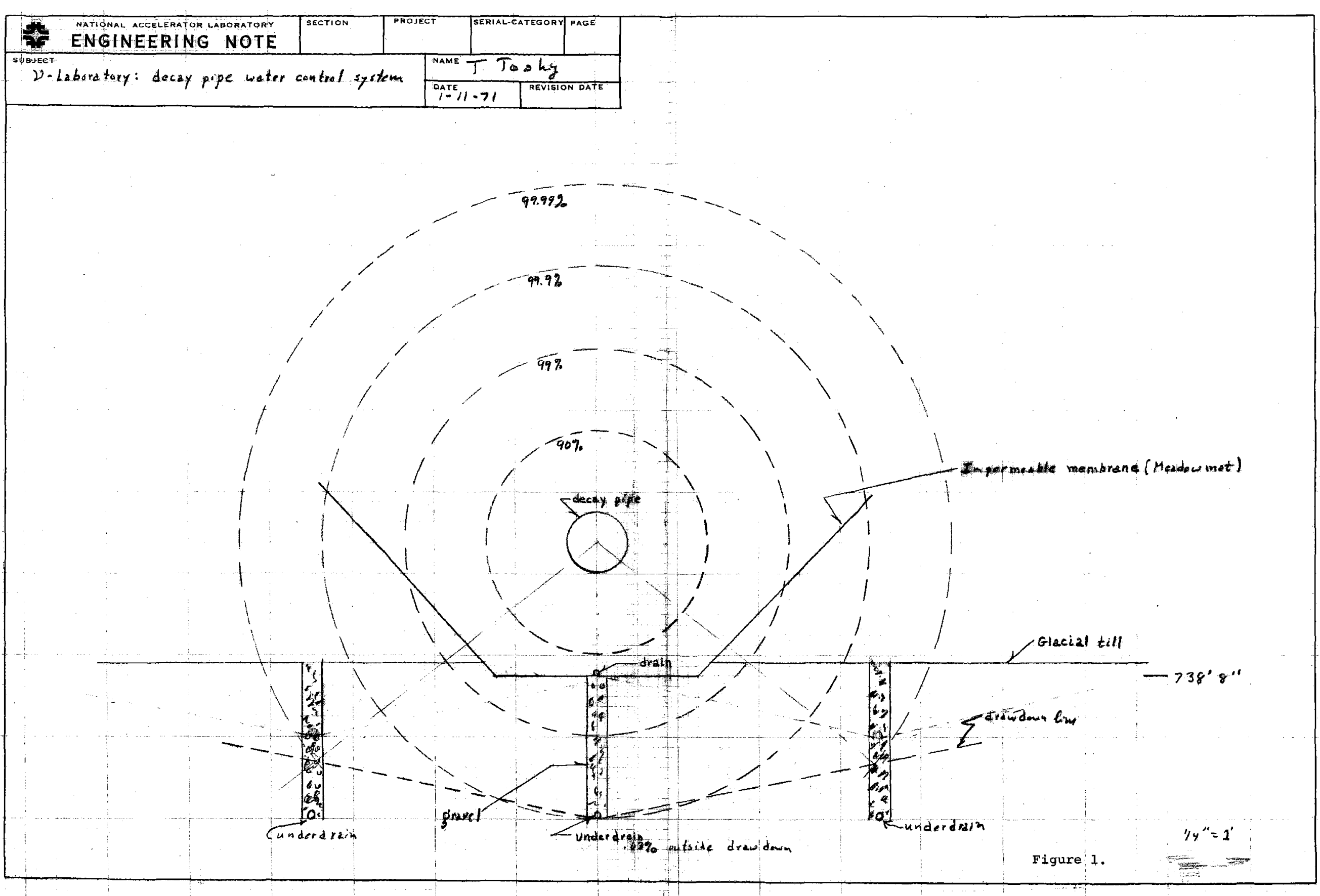




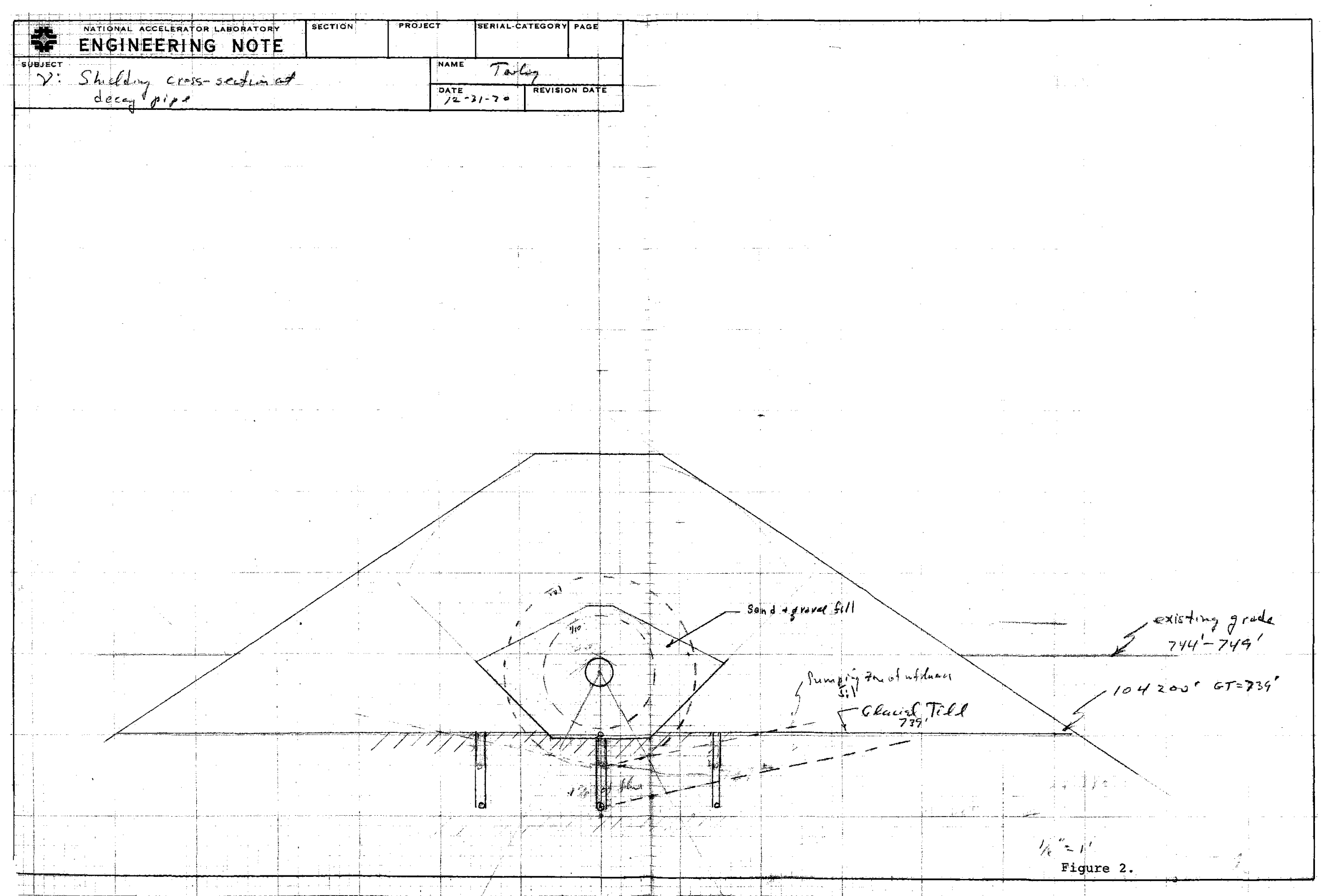

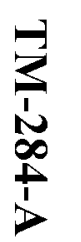

